\title{
Hemoperitoneum: a complication of loop electrosurgical excision procedure
}

\author{
Angela Cho ${ }^{1}$, Sunwha Park', Soyun Park ${ }^{2}$, Hye Sim Kang ${ }^{2}$, Soon Sup Shim², Chul Min Park², Sung Yob Kim² \\ Department of Obstetrics and Gynecology, ${ }^{1}$ Ewha Womans University Mokdong Hospital, Seoul, ${ }^{2}$ Jeju National University Hospital, Jeju, Korea
}

Loop electrosurgical excision procedure (LEEP) is commonly performed for the management of cervical intraepithelial neoplasia. Although LEEP is considered to be a relatively simple procedure, several unexpected complications have been reported in the literature. Herein, we report a case of hemoperitoneum caused by uterine perforation following LEEP. Blood collection in pelvic cavity and two small defects of the uterus were confirmed by diagnostic laparoscopy. The defects were sutured and the patient recovered well after the operation.

Keywords: Conization; Laparoscopy; Hemoperitoneum

\section{Introduction}

Loop electrosurgical excision procedure (LEEP) is the preferred management for a high-grade squamous intraepithelial lesion (HSIL). Common complications of LEEP are vaginal bleeding, preterm delivery, and cervical stenosis [1]. Unusual complications of LEEP are postoperative peritonitis, vesicovaginal fistula, vaginal evisceration, and lower urinary tract injury [2-5]. Hemoperitoneum is a rare complication after LEEP, according to the available literature. Herein, we present a case of hemoperitoneum following LEEP.

\section{Case report}

A 27-year-old woman, gravida 1 para 1, was referred for the management of HSIL. LEEP was performed uneventfully under monitored anesthesia care using propofol. A $2.4 \times 2.8 \times 0.8 \mathrm{~cm}$ sized specimen was obtained after multiple passes with $1.5 \times 1.5 \mathrm{~cm}$ sized electrodes. A little bleeding that was observed at the 6-o'clock position on the cervix was electrocoagulated and sutured with Vicryl 2-0 $0^{\circledR}$ (Ethicon, Somerville, NJ, USA), encircling the posterior part of the cervical os. Then, a piece of gauze was packed in vagina for compression.

An hour after operation, she experienced upper abdominal pain. We removed the gauze and examined her cervix, but the findings were nonspecific. Two hours after operation, her blood pressure measured $84 / 43 \mathrm{mmHg}$ and pulse rate was 82 beats per minute. She responded well to intravenous fluid resuscitation and the blood pressure recovered to $108 / 63 \mathrm{mmHg}$, and the pulse to 73 beats per minute. Blood tests revealed a reduced hemoglobin level of $10.6 \mathrm{~g} / \mathrm{dL}$ from the preoperative hemoglobin level of $12.0 \mathrm{~g} / \mathrm{dL}$. Her abdominal pain was relieved after defecation, but she complained of persisting bilateral subcostal pain. Postoperative radiographs of the abdomen and chest did not reveal any concerning findings. Next morning, her hemoglobin level had further reduced to $9.2 \mathrm{~g} / \mathrm{dL}$. As no vaginal bleeding had occurred postoperatively, this reduction could not be attributed much to hemodilution.

Typically, patients undergoing LEEP in our hospital are discharged one day after the procedure. We postponed discharge because her clinical course was not usual. Abdominal and pelvic contrast-enhanced computed tomography (CT)

Received: 2018.04.24. Revised: 2018.06.27. Accepted: 2018.07.16. Corresponding author: Sung Yob Kim

Department of Obstetrics and Gynecology, Jeju National University Hospital, 15 Aran 13-gil, Jeju 63241, Korea

E-mail: kimsy@jejunu.ac.kr

https://orcid.org/0000-0001-8424-7219

Articles published in Obstet Gynecol Sci are open-access, distributed under the terms of the Creative Commons Attribution Non-Commercial License (http://creativecommons. org/licenses/by-nc/3.0/) which permits unrestricted non-commercial use, distribution, and reproduction in any medium, provided the original work is properly cited.

Copyright (c) 2019 Korean Society of Obstetrics and Gynecology 


\section{Obstetrics \& Gynecology Science}

Angela Cho, et al. Hemoperitoneum: a complication of LEEP

was performed to assess the cause of her abdominal discomfort. Imaging studies revealed a moderate amount of blood collection in the pelvic cavity and no observable active bleeding site (Fig. 1). Ectopic pregnancy was excluded as her beta human chorionic gonadotropin levels were less than 0.100 $\mathrm{mIU} / \mathrm{mL}$. Transvaginal ultrasonography found fluid collection in the posterior cul-de-sac and no abnormal findings in the uterus and adnexa.

To pinpoint the origin of the bleeding site and the cause of hemoperitoneum, diagnostic laparoscopy was performed. A uterine manipulator was not used during operation because her cervix was friable due to LEEP. On entering the peritoneal cavity, approximately $500 \mathrm{~mL}$ of old blood was noted (Fig. 2A). After removal of the blood collection, the abdominopelvic cavity was thoroughly inspected. There were

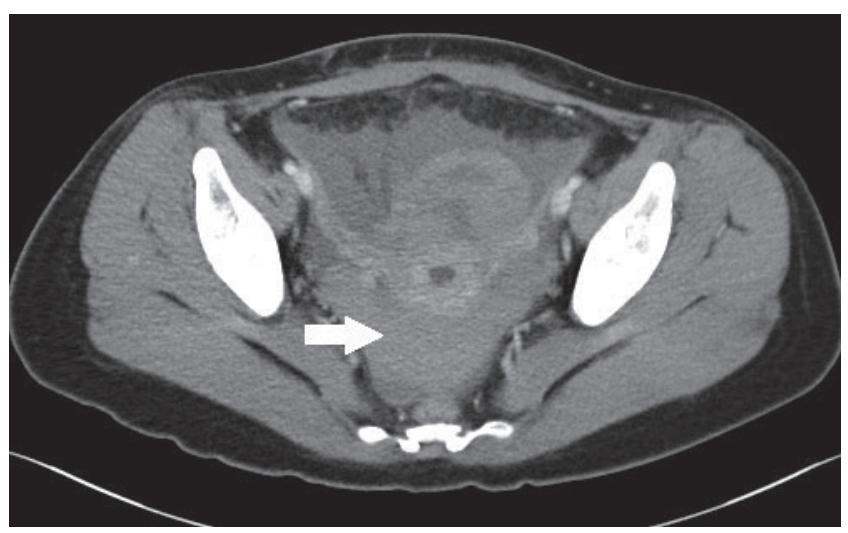

Fig. 1. Abdominal and pelvic contrast-enhanced computed tomography showing fluid collection in pelvic cavity (arrow). two $0.5 \mathrm{~cm}$ sized symmetric defects above both uterosacral ligaments without active bleeding (Fig. 2B). Since there was no other abnormal finding in abdominopelvic cavity, we suspected that these defects had caused the hemoperitoneum. After the defects were sutured laparoscopically using Vicryl 2-0 ${ }^{\circledast}$ (Ethicon), a diagnostic cystoscopy was performed. Indigo carmine was injected intravenously and excretion of dyed urine through both ureteral orifices was observed. The postoperative course was uneventful, and she was discharged on the third postoperative day.

\section{Discussion}

LEEP is a common procedure that is performed in cases of cervical intraepithelial neoplasia (CIN) using a small wire loop and electric current [6]. Common complications of LEEP are vaginal bleeding, infection, cervical stenosis, and cervical incompetence $[1,7]$. Peritonitis, vesicovaginal fistula, vaginal evisceration, and lower urinary tract injury have been reported as unusual complications [2-5]. To avoid iatrogenic injury during LEEP, profound understanding of anatomy is necessary.

The cervix of the woman of reproductive age measures 3.5 $\mathrm{cm}$ in length and $2 \mathrm{~cm}$ in diameter [8]. After menopause, atrophic changes of cervix are common. Merz at al. [9] reported that the mean cervical length of women who had been postmenopausal at least 5 years was $2.4 \mathrm{~cm}$. Therefore, the use of extremely large electrodes (e.g., $20 \times 20 \mathrm{~mm}$ ) may
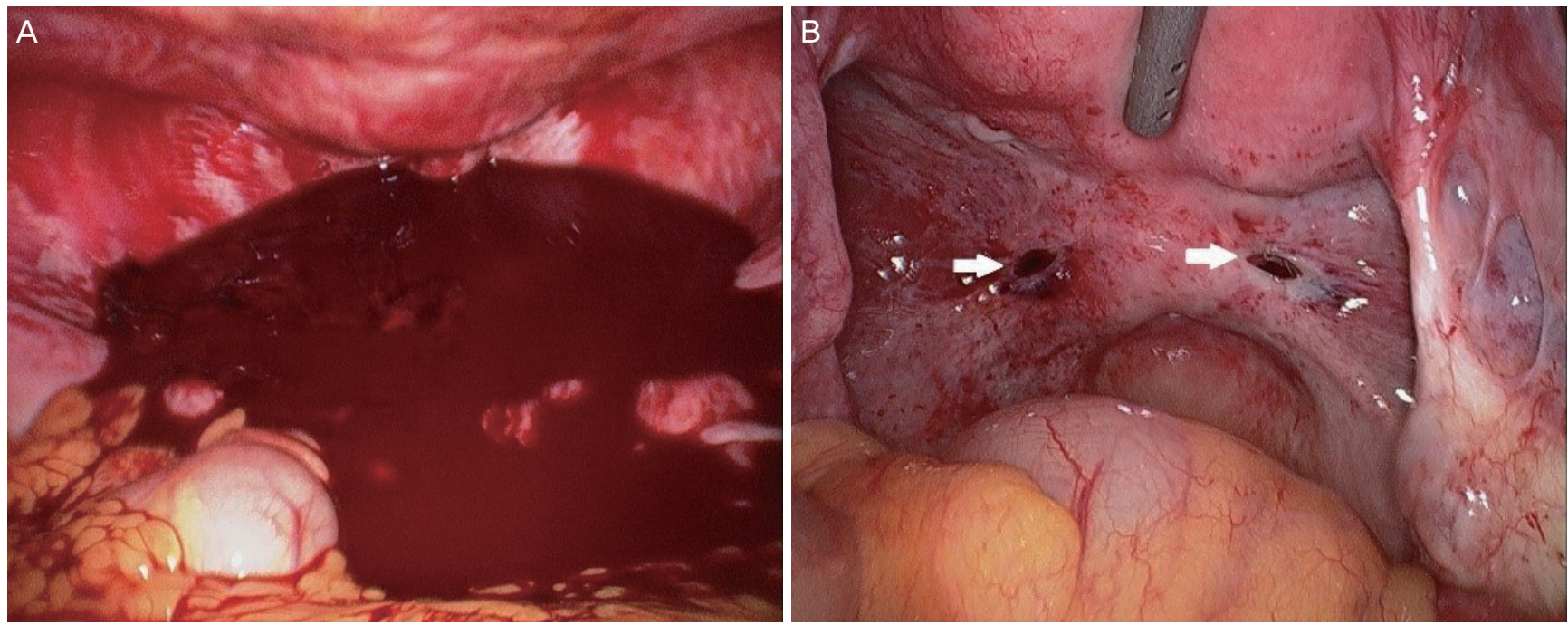

Fig. 2. Hemoperitoneum (A) and defects (arrows) of the uterus (B) confirmed by laparoscopy. 


\section{Obstetrics \& Gynecology Science}

Vol. 62, No. 2, 2019

lead to injury of the vaginal walls, rectum, and bladder [7]. If the diameter of a lesion is larger than $2 \mathrm{~cm}$, the lesion must be removed with multiple passes using one or more sizes of loop [10]. If there is marked atrophy due to estrogen deficiency in older women, it is advisable to delay LEEP until after a course of topical estrogen treatment [10].

Several studies have shown that the endocervical mucosa projects $3 \mathrm{~mm}$ into the underlying stroma but may plunge as deep as $6 \mathrm{~mm}$ [8]. CIN can penetrate the stroma a depth of 3 to $3.5 \mathrm{~mm}$ and rarely to a depth of up to $6 \mathrm{~mm}$ [11]. Therefore, if the lesion involves the endocervical canal, the depth of excision should be at least $6 \mathrm{~mm}$. The preferred depth of the excision is 7 to $8 \mathrm{~mm}$, and a "top-hat" technique can be used for deep endocervical lesions [7]. As the depth of excision increases, the risk of bleeding and stenosis increases [10]. For this reason, if the lesion extends more than $1 \mathrm{~cm}$ into the canal, LEEP should not be used [10].

We suspect that the hemoperitoneum in our case was caused by uterine perforation. Unintentional colpotomy during the procedure may have occurred during electrocoagulation or suturing for hemostasis. Several risk factors of iatrogenic injury during LEEP have been reported in the literature. Moon et al. [12] reported that deep suturing during conization resulted in the formation of a hematoma adjacent to the uterine artery. Ghassani et al. [4] reported that the use of monopolar coagulation in an atrophic cervix caused iatrogenic colpotomy during LEEP. Cho et al. [3] suggested that atrophic cervix and endocervical lesion are risk factors of over-extended excision of cervix and injury of adjacent tissue. In addition, the placement of the suture through both anterior and posterior lips of cervix before the procedure may have enabled a precise cut of the cervix and reduced complications [13].

We identified only one case report of abdominal bleeding following LEEP by searching in PubMed [14]. Since hemoperitoneum is uncommon after LEEP, it is easy to be overlooked. Furthermore, LEEP is usually performed at the outpatient clinic and complications except vaginal bleeding can be easily neglected. Our case illustrates the difficulties in early diagnosis of hemoperitoneum following LEEP. Moreover, when the patient is hemodynamically stable, the physician may be unaware of the presence of hemoperitoneum. Similarly, a minor hemoperitoneum after LEEP can be underreported.

In our case, we confirmed the defects of the uterus by laparoscopy. Uterine perforation can cause bowel perforation or peritonitis as well as hemoperitoneum $[2,12]$. Therefore, when a patient complains of abdominal pain after LEEP, physicians should postpone the discharge and observe the clinical course of the patient carefully. In addition, ultrasonography or CT can be useful diagnostic tools for a patient with unexplained abdominal pain after LEEP.

\section{Conflict of interest}

No potential conflict of interest relevant to this article was reported.

\section{Patient consent}

The patients provided written informed consent for the publication and the use of their images.

\section{References}

1. Garcia F, Hatch KD, Berek JS. Intraepithelial disease of the cervix, vagina, and vulva. In: Berek JS, Novak E, editors. Berek \& Novak's gynecology. 15th ed. Philadelphia (PA): Lippincott Williams \& Wilkins; 2012. p.592-604.

2. Varras M, Akrivis C, Anastasiadis A, Lekkas G, Diakakis G. Peritonitis due to iatrogenic colpotomy after large loop excision of the transformation zone (LLETZ) in a patient with cervical intraepithelial neoplasia III: our experience of a rare case with review of the literature. Eur J Gynaecol Oncol 2012;33:214-6.

3. Cho SS, Kang WD, Kim SM, Choi SH. A case of vesicovaginal fistula after loop electrosurgical excisional procedure. Korean J Obstet Gynecol 2011;54:390-4.

4. Ghassani A, Andre B, Simon-Toulza C, Tanguy le Gac Y, Martinez A, Vidal F. Vaginal evisceration: an unexpected complication of conization. Case Rep Obstet Gynecol 2014;2014:983682.

5. Contag SA, Wilson TO. Ureteral injury during cold-knife cervical conization. J Pelvic Med Surg 2004;10:81-3.

6. Guido R, Lonky NM, Diedrich J. Secondary prevention of cervical cancer part 3: evidence-based management of women with cervical intraepithelial neoplasia. Clin Obstet Gynecol 2014;57:302-15. 


\section{Obstetrics \& Gynecology Science}

Angela Cho, et al. Hemoperitoneum: a complication of LEEP

7. Massad LS. Cervical cancer precursors and their management. In: Jones HW, Rock JA, editors. Te Linde's operative gynecology. 11th ed. Philadelphia (PA): Wolters Kluwer; 2015. p.1185-9.

8. Baggish MS. Anatomy of the cervix. In: Baggish MS, Karram MM, editors. Atlas of pelvic anatomy and gynecologic surgery. 4th ed. Philadelphia (PA): Elsevier; 2016. p.493-7.

9. Merz E, Miric-Tesanic D, Bahlmann F, Weber G, Wellek $S$. Sonographic size of uterus and ovaries in pre- and postmenopausal women. Ultrasound Obstet Gynecol 1996;7:38-42.

10. Sellors JW, Sankaranarayanan R. Treatment of cervical intraepithelial neoplasia by loop electrosurgical excision procedure (LEEP). In: Sellors JW, Sankaranarayanan R, editors. Colposcopy and treatment of cervical intraepi- thelial neoplasia: a beginners' manual. Lyon: International Agency for Research on Cancer; 2003. p.103-11.

11. Baggish MS. Conization of the cervix. In: Baggish MS, Karram MM, editors. Atlas of pelvic anatomy and gynecologic surgery. 4th ed. Philadelphia (PA): Elsevier; 2016. p. 505-18.

12. Moon G, Jeon S, Nam KH, Choi S, Sunwoo J, Ryu A. Pseudoaneurysm of uterine artery causing intra-abdominal and vaginal bleeding after cervical conization. Obstet Gynecol Sci 2015;58:256-9.

13. Bornstein J, Harroch J, Morad E. Traction suture of the cervix: a novel procedure with loop electrosurgical excision. Obstet Gynecol 2003;102:1063-5.

14. Nannapaneni P, Naik R, de Barros Lopes A, Monaghan JM. Intra-abdominal bleed following LLETZ. J Obstet Gynaecol 2002;22:99-100. 